\title{
MORFOGÊNESE EM CULTIVARES DE PANICUM AVALIADAS EM DIFERENTES ÉPOCAS NO NORDESTE DO BRASIL
}

\section{MORPHOGENESIS PANICUM OF DIFFERENT CULTIVARS EVALUATED AT DIFFERENT SEASONS IN NORTHEAST BRAZIL}

Emmanuel L. de Lima Véras ${ }^{1}$; Jéssica Gomes Rodrigues²; Antônio Leandro Chaves Gurguel ${ }^{2}$; Brenda Adelino de Macêdo Campelo ${ }^{3}$; Gelson dos Santos Difante ${ }^{4}$

DOI: https://doi.org/10.31692/978-65-991061-7-0.408-413 “

\section{INTRODUÇÃO}

Durante as últimas décadas vários lançamentos de cultivares contribuíram para um grande número de opções de plantas disponíveis para o setor pecuário. Os lançamentos são frutos de pesquisas que buscam forrageiras que sejam resistentes, produtivas e perenes nas diferentes localizações geográficas. Entretanto, ainda existem relatos de insucesso devido à falta de conhecimento na escolha da planta forrageira. Apesar de trabalhosos, os estudos de morfogênese permitem o conhecimento das respostas das plantas forrageiras em diferentes biomas. Também fornecem uma visão geral do padrão de crescimento das plantas, contribuindo para uma melhor compreensão da sua funcionalidade, gerando conhecimentos necessários para planejar e definir estratégias adequadas de manejo (Barbosa et al., 2007). O objetivo desse estudo foi avaliar as características morfogênicas de cultivares de Panicum maximum (cvs): Aruana, Massai, Mombaça, Tamani, Tanzânia, Zuri no Nordeste brasileiro.

\section{FUNDAMENTAÇÃO TEÓRICA}

A avaliação do fluxo de biomassa das plantas é o principal meio de investigação do seu comportamento nas diferentes fases do seu desenvolvimento, onde as condições climáticas e ambientais influenciam as respostas morfogênicas e estruturas das forrageiras. A morfogênese retrata a dinâmica de aparecimento e expansão dos componentes das plantas no espaço, resultado da taxa de surgimento de novos órgãos e do balanço entre sua taxa de crescimento e senescência, sendo expressa em taxas de aparecimento, expansão e senescência ou duração de vida destes componentes (Chapman; Lemaire, 1993).

Entre os gêneros, o P. maximum é amplamente cultivado em todas as áreas tropicais do mundo, no Brasil de acordo com Valle et al., (2009), é a espécie forrageira propagada por

\footnotetext{
${ }^{1}$ Doutorando, Programa de Pós-graduação em Ciência Animal/FAMEZ/UFMS, emmanuel.veras@ hotmail.com

${ }^{2}$ Mestrando (a), Programa de Pós-graduação em Produção Animal/UEACIA/UFRN, jessicagr@outlook.com

3 Graduanda em Agronomia, Universidade Federal do Rio Grande do Norte, brendadelino@gmail.com

${ }^{4}$ Bolsista de Produtividade CNPq, Programa de Pós-graduação em Ciência Animal/FAMEZ/UFMS, gdifante@hotmail.com
} 
semente mais produtiva do mercado, justificado pela sua alta capacidade de adaptação aos vários tipos de clima e solos. Lançamentos recentes como o BRS Zuri e o híbrido BRS Tamani, lançados em 2014 e 2015 respectivamente, pelo CNPGC-EMBRAPA, ganharam visibilidade comercial pelas recomendações de facilidade de cultivo e maior resistência ao estresse biótico e/ou abiótico.

\section{METODOLOGIA}

O experimento foi conduzido na área experimental do GEFOR - Grupo de Estudos em Forragicultura, na Unidade Acadêmica Especializada em Ciências Agrárias UEACIA/UFRN, de 10/04/2016 a 01/04/2017. Os períodos de avaliações foram de acordo com o regime pluviométrico da região. A área experimental foi composta por 24 parcelas de 4,0 $\mathrm{m}^{2}$, com 1,69 $\mathrm{m}^{2}$ de área útil, divididas igualmente entre quatro blocos. Os tratamentos avaliados foram seis cultivares de Panicum maximum: Aruana, Massai, Mombaça, Tamani, Tanzânia e Zuri. Para avaliação das características morfogênicas foram monitorados três perfilhos por parcela no início de cada período de rebrotação. Os perfilhos foram marcados com fios coloridos, com a finalidade de facilitar a identificação visual.

As avaliações foram realizadas a cada sete dias, e foram tomadas as medidas do comprimento total das lâminas foliares (Expandidas e emergentes), o número de folhas, comprimento do pseudocolmo (colmo + bainha), tomando a distância da base do perfilho até a última lígula exposta. De posse dos resultados foram determinadas as seguintes variáveis: Taxa de alongamento de colmo, TAlC (cm/perfilho.dia); Comprimento final da folha, CFF (cm/perfilho.dia); Número de folhas vivas, NFV Taxa de Aparecimento de Folhas, (TApF) (folhas/perfilho.dia); Filocrono FIL (inverso da TApF); Taxa de Alongamento de Folhas, TAlF (cm/perfilho.dia); Duração de Vida da folha, DVF - (dias), e Taxa de Senescência, TseF (cm/perfilho.dia). O delineamento foi em blocos ao acaso. Utilizou-se as épocas como medidas repetidas no tempo. Os dados foram submetidos à análise de variância e o efeito das fontes de variação e suas interações verificadas pelo teste de Tukey a 5\% de significância.

\section{RESULTADOS E DISCUSSÕES}

Houve interação cultivares x épocas do ano $(\mathrm{P}=0,0383)$, para a taxa de alongamento de colmo (TAlC). Foi observado maior TAlC na cultivar Zuri e menor nas cultivares Aruana, Tamani e Tanzânia, com valores intermediários para as demais cultivares nas águas de 2017. Não sendo observado diferença para a TAlC entre as cultivares nas demais épocas do ano (Tabela 1). As águas de 2017 registrou maior acumulado de chuvas entre os períodos 
avaliados, a maior disponibilidade de água pode ter contribuído para elevação do meristema apical, decorrido do processo de alongamento de entrenós. Tal característica também é atribuída a ambientes com luz, priorizando alocação de carbono nessa estrutura. A maior TAlC pode ter contribuído para a maior taxa de senescência observada nesse cultivar, principalmente nas folhas localizadas na base do dossel.

A interação entre cultivar e época do ano foi significativa $(\mathrm{P}=0,0001)$ para comprimento final da folha (CFF), os maiores valores foram observados na cultivar Mombaça, que não diferiu da cultivares Zuri e Tanzânia nas águas de 2016, enquanto que nas águas de 2017 apenas o Zuri não diferiu do Mombaça, já no período seco a cultivar Mombaça apresentou maior CFF. Independente da época, os maiores CFF foram registrados nas forrageiras de maior porte, evidenciando que maiores comprimentos da bainha são desencadeados pelas altas taxas alongamento de lâminas foliares. Castagnara et al., (2014), destacaram que as cultivares do gênero Panicum devido seu hábito de crescimento favorecem o aglomerado de células de desenvolvimento com o avanço da idade da planta, resultando em aumento no comprimento da bainha.

Tabela 1 - Médias de características morfogênicas e coeficientes de variação (\%) em seis cultivares de Panicum maximum em diferentes épocas do ano

\begin{tabular}{|c|c|c|c|c|c|c|}
\hline \multirow[b]{2}{*}{ Épocas } & Aruana & Massai & Mombaça & Tamani & Tanzânia & Zuri \\
\hline & \multicolumn{6}{|c|}{ Taxa de Alongamento de Colmo (cm/perfilho.dia) $-(\mathrm{CV}=24,58 \%)$} \\
\hline Águas 2016 & $0,16 \mathrm{Aa}$ & $0,07 \mathrm{Ba}$ & $0,08 \mathrm{Ba}$ & $0,07 \mathrm{Ba}$ & $0,14 \mathrm{Aa}$ & $0,10 \mathrm{Ba}$ \\
\hline Seca & $0,04 \mathrm{Ba}$ & $0,07 \mathrm{Ba}$ & $0,05 \mathrm{Ba}$ & $0,09 \mathrm{Ba}$ & $0,03 \mathrm{Ba}$ & $0,12 \mathrm{Ba}$ \\
\hline \multirow[t]{2}{*}{ Águas 2017} & $0,18 \mathrm{Ab}$ & $0,28 \mathrm{Aab}$ & $0,28 \mathrm{Aab}$ & $0,16 \mathrm{Ab}$ & $0,11 \mathrm{Ab}$ & $0,41 \mathrm{Aa}$ \\
\hline & \multicolumn{6}{|c|}{ Comprimento final da folha $(\mathrm{cm} /$ perfilho.dia $)-(\mathrm{CV}=21,24 \%)$} \\
\hline Águas 2016 & $12,00 \mathrm{Ab}$ & $20,25 \mathrm{Ab}$ & $53,33 \mathrm{Aa}$ & $26,50 \mathrm{Ab}$ & $41,33 \mathrm{Aab}$ & $38,41 \mathrm{Aab}$ \\
\hline Seca & $7,41 \mathrm{Bc}$ & $12,11 \mathrm{Bbc}$ & $21,83 \mathrm{Ba}$ & $16,11 \mathrm{Bbc}$ & $20,66 \mathrm{Bb}$ & $18,58 \mathrm{Bbc}$ \\
\hline Águas 2017 & $18,33 \mathrm{Ac}$ & $32,00 \mathrm{Abc}$ & $56,83 \mathrm{Aa}$ & $27,83 \mathrm{Ab}$ & $30,08 \mathrm{Abc}$ & $42,50 \mathrm{Aab}$ \\
\hline \multicolumn{7}{|c|}{ Número de folhas vivas (folhas/perfilho) - $(\mathrm{CV}=12,75 \%)$} \\
\hline Águas 2016 & $4,91 \mathrm{Aa}$ & $4,08 \mathrm{Aab}$ & $4,16 \mathrm{Aab}$ & $3,91 \mathrm{Ab}$ & $5,00 \mathrm{Aa}$ & $4,16 \mathrm{Aab}$ \\
\hline Seca & $2,58 \mathrm{Bab}$ & $2,88 \mathrm{Bab}$ & $2,77 \mathrm{Bab}$ & $2,33 \mathrm{Bab}$ & $2,08 \mathrm{Bb}$ & $3,16 \mathrm{Ba}$ \\
\hline Águas 2017 & $4,66 \mathrm{Aa}$ & 4,88Aa & $4,25 \mathrm{Aa}$ & $3,08 \mathrm{Aa}$ & $3,16 \mathrm{Aa}$ & $4,58 \mathrm{Aa}$ \\
\hline
\end{tabular}

Medias seguida de letras maiúsculas na coluna ou minúsculas na linha diferem entre si pelo teste de Tukey a 5\% de significância $(\mathrm{P}<0,05)$.

A interação entre cultivar e época do ano foi significativa $(\mathrm{P}=0,0068)$ para número de folhas vivas (NFV). Os maiores valores para o NFV foram registrados nos capins Aruana e Tanzânia nas águas de 2016, na seca o maior NFV foi verificado na cultivar Zuri menor na Tanzânia e intermediário nas demais forrageiras, nas águas de 2017 não houve diferença entre as cultivares. O NFV é uma característica genotípica estável apenas na ausência de deficiências, é possível que o comportamento do capim Tanzânia em expressar maior número de folhas nas águas de 2016 e menor na seca seja um indício de variação da produção de 
forragem dessa forrageira as variações impostas nos períodos de águas e estiagem.

Não houve interação cultivar e época do ano para as demais variáveis avaliadas $(\mathrm{P}>0,005)$. Também não foi observado efeito de cultivar para duração de vida da folha DVF $(\mathrm{P}=0,0835)$ (Tabela 2), a ausência de variação entre os cultivares para a DVF, sugerem que as cultivares apresentaram padrão semelhante de renovação dos tecidos, de acordo com Nabinger (1998) é determinado geneticamente e pouco variável.

A taxa de aparecimento de folhas variou entre as cultivares $(\mathrm{P}=0,0041)$, sendo o maior valor registrado para o capim Aruana, menor no Massai, Tamani e Tanzânia, e intermediário no Mombaça e Zuri. A maior TApF verificada no cultivar Aruana pode ser atribuído ao fato dessa forrageira ter apresentado maior dificuldade para estabelecimento, e na estiagem, o que ocasionou diminuição no surgimento de duas folhas consecutivas e portanto, aumento na TApF. Os resultados do Filocrono $(\mathrm{P}=0,0161)$ seguiram comportamento oposto a TApF, o maior valor foi registrado na cultivar Tamani, menor na Aruana e demais forrageiras com resultados intermediários. O aumento no aparecimento de novas folhas contribuiu para o aumento da senescência observados no capim Aruana.

Tabela 2 - Médias de características morfogênicas e coeficientes de variação (\%) em seis cultivares de Panicum maximum

\begin{tabular}{cccccccc}
\hline Variáveis & Aruana & Massai & Mombaça & Tamani & Tanzânia & Zuri & CV (\%) \\
\hline TApF & $0.07 \mathrm{a}$ & $0.05 \mathrm{~b}$ & $0.06 \mathrm{ab}$ & $0.05 \mathrm{~b}$ & $0.05 \mathrm{~b}$ & $0.06 \mathrm{ab}$ & 36.69 \\
FIL & $18.34 \mathrm{~b}$ & $24.20 \mathrm{ab}$ & $21.78 \mathrm{ab}$ & $28.25 \mathrm{a}$ & $22.53 \mathrm{ab}$ & $26.44 \mathrm{ab}$ & 58.54 \\
TAlF & $1.62 \mathrm{c}$ & $1.76 \mathrm{c}$ & $3.09 \mathrm{a}$ & $1.83 \mathrm{c}$ & $2.19 \mathrm{bc}$ & $2.78 \mathrm{ab}$ & 44.18 \\
DVF & $58.02 \mathrm{a}$ & $71.07 \mathrm{a}$ & $69.92 \mathrm{a}$ & $79.54 \mathrm{a}$ & $66.53 \mathrm{a}$ & $92.19 \mathrm{a}$ & 68,61 \\
TseF & $0.61 \mathrm{ab}$ & $0.28 \mathrm{~b}$ & $0.56 \mathrm{ab}$ & $0.55 \mathrm{ab}$ & $0.55 \mathrm{ab}$ & $0.93 \mathrm{a}$ & 60,05 \\
\hline
\end{tabular}

Médias seguida de letras minúsculas distintas na linha diferem pelo teste de Tukey a $5 \%$ de significância $(\mathrm{p}<0,05)$. Taxa de Apar. de Folhas, TApF (folhas/perfilho.dia); Filocrono FIL; Taxa de Alon. de Folhas, TAlF (cm/perfilho.dia); Comprimento final da folha, CFF (cm/perfilho.dia); Duração de Vida da folha, DVF - (dias); Taxa de Senescência, TseF (cm/perfilho.dia); Taxa de alon. de colmo, TAlC ( $\mathrm{cm} /$ perfilho.dia) e Número de folhas vivas, NFV.

A maior taxa de alongamento de folha foi verificada na cultivar Mombaça, menor nas cultivares Aruana, Massai e Tamani e intermediária na Tanzânia e Zuri ( $\mathrm{P}=0,0000)$. Entre as forrageiras, algumas diferem entre si quanto à forma da utilização dos recursos disponíveis priorizando desenvolvimento de massa de forragem, isso pode ser atribuído as maiores folhas do capim Mombaça que respondem com altas taxas de alongamento foliar.

Para a taxa de senescência maiores taxas foram avaliadas na cultivar Zuri e menor no Massai, as demais forrageiras com taxas intermediárias $(\mathrm{P}=0,0090)$. A cultivar Massai se destaca pelo seu potencial de uso em regiões onde a precipitação é baixa com elevadas temperaturas, Martuscello et al., (2015) reforça que os estudos com capim-massai são incipientes na região Nordeste, não havendo, portanto, base comparativa para algumas 
características morfogênicas e estruturais. Entretanto, a presença de folhas verdes no dossel é um bom indicador do potencial agronômico da forrageira, (Martuscello et al., 2015), por representar o potencial para produção de fotoassimilados, com consequente aumento nas taxas respiratórias e maior produção de massa seca de folhas.

Tabela 3 - Variáveis morfogênicas e coeficientes de variação (\%) de cultivares forrageiras avaliadas em diferentes épocas

\begin{tabular}{ccccc}
\hline Variável & Águas 2016 & Seca & Águas 2017 & CV (\%) \\
\hline Taxa de Apar. de Folhas (folhas/perfilho.dia) & $0,04 \mathrm{~B}$ & $0,03 \mathrm{~B}$ & $0,09 \mathrm{~A}$ & 20,03 \\
Filocrono & $25,05 \mathrm{~B}$ & $34,08 \mathrm{~A}$ & $12,12 \mathrm{C}$ & 24,48 \\
Taxa de Alon. de Folhas (cm/perfilho.dia) & $2,20 \mathrm{~B}$ & $1,23 \mathrm{C}$ & $3,08 \mathrm{~A}$ & 24,58 \\
Duração de Vida da folha - dias & $100,58 \mathrm{~A}$ & $93,13 \mathrm{~A}$ & $27,26 \mathrm{~B}$ & 29,35 \\
Taxa de Senescência (cm/perfilho.dia) & $0,61 \mathrm{AB}$ & $0,73 \mathrm{~A}$ & $0,42 \mathrm{~B}$ & 70,05 \\
\hline
\end{tabular}

Médias seguida de letras minúsculas ou maiúscula distintas na linha diferem pelo teste de Tukey a $5 \%$ de significância $(\mathrm{p}<0,05)$.

As maiores taxas de aparecimento de folhas $(\mathrm{P}=0,0000)$, foram registradas nas águas de 2017 (Tabela 3), período de maior precipitação entre os avaliados. Em condições desejadas de umidade no solo, a água é responsável pela manutenção da turgescência das células, o que contribuiu provavelmente para uma alta taxa fotossintética e altas taxas de alongamento foliar, essa última sendo extremamente sensível à disponibilidade de água.

O filocrono foi influenciado pelas épocas do ano, o menor valor foi verificado nas águas de 2017, seguido das águas de 2016 e maior na seca $(\mathrm{P}=0,0000)$. Este comportamento é resultado da relação entre características morfogênicas e estruturais do dossel, na época de maior precipitação houve crescimento acelerado da bainha, consequentemente, o tempo necessário para a completa expansão das lâminas foliares foi menor.

A duração de vida das folhas foi menor nas águas de 2017 e maior nos demais períodos avaliados $(\mathrm{P}=0,0000)$. Com o aumento das taxas de crescimento das folhas é normal que ocorre um incremento no tornover das plantas e as folhas durem menor quantidade de tempo, em decorrência da elevada renovação dos tecidos desencadeado pela alta precipitação. Contrariamente, maior taxa de senescência foram verificadas na época seca $(\mathrm{P}=0,0003)$. Tal observação reforça que as plantas não têm crescimento constante ao longo das estações, inúmeros fatores atuam na expressão fenotípica do aparecimento de folhas, sendo uma das principais a precipitação.

\section{CONCLUSÕES}

As forrageiras apresentam potencial de utilização nas condições que foram avaliadas. Entre as forrageiras o capim-aruana se destacou por apresentar menor resistência ao período seco. A época de maior concentração de chuva favoreceu maior desenvolvimento das 
características morfogênicas, e menores perdas por senescência.

\section{REFERÊNCIAS}

BARBOSA, R. A.; NASCIMENTO JUNIOR, D.; EUCLIDES, V. P. B.; Capim-tanzânia submetido a combinações entre intensidade e frequência de pastejo. Pesquisa Agropecuária Brasileira, v. 42, n. 3, p. 329-340, mar. 2007.

CASTAGNARA, D. D.; ZOZ, T.; KRUTZMANN, A.; UHLEIN, A.; MESQUITA, E. E.; NERES, M. A.; OLIVEIRA, P. S. R. Produção de forragem, características estruturais e eficiência de utilização do nitrogênio em forrageiras tropicais sob adubação Nitrogenada. Semina: Ciências Agrárias, Londrina, v. 32, n. 4, p. 16371648, out./dez. 2014.

CHAPMAN, D.; LEMAIRE, G. Morphogenetic and structural determinants of plant regrowth after defoliation. In: International Grassland Congress, 17, Palmerston North. anais... Palmerston North. p.95-104, 1993

MARTUSCELLO, J. O.; BRAZ, T. G. S.; JANK, L.; CUNHA, D. N. F. V.; CARVALHO, A. L. S. Identification of ideotypes by canonical analysis in panicum maximum. Ciênc. Agrotec., Lavras, v.39, n.2, p.147-153, 2015.

NABINGER, C. Princípios de manejo e produtividade de pastagens. In: CICLO DE PALESTRAS EM PRODUÇÃO E MANEJO DE BOVINOS DE CORTE, 3., 1998, Canoa. Anais... Canoa: Editora da ULBRA, p.54-107, 2008.

VALLE, C.B.; JANK. L.; RESENDE, R.MS.; O melhoramento de forrageiras tropicais no Brasil. Revista Ceres, v. 56, n.4, p.460-472, 2009. 